\title{
Proteinase-Activated Receptor 2-Mediated Potentiation of Transient Receptor Potential Vanilloid Subfamily 1 Activity Reveals a Mechanism for Proteinase-Induced Inflammatory Pain
}

\author{
Yi Dai, ${ }^{1}$ Tomoko Moriyama, ${ }^{2}$ Tomohiro Higashi, ${ }^{2}$ Kazuya Togashi, ${ }^{2}$ Kimiko Kobayashi, ${ }^{1}$ Hiroki Yamanaka, ${ }^{1}$ \\ Makoto Tominaga, ${ }^{2}$ and Koichi Noguchi ${ }^{1}$ \\ ${ }^{1}$ Department of Anatomy and Neuroscience, Hyogo College of Medicine, Hyogo 663-8501, Japan, and ${ }^{2}$ Department of Cellular and Molecular Physiology, \\ Mie University School of Medicine, Tsu, Mie 514-8507, Japan
}

\begin{abstract}
Proteinase-activated receptor (PAR) 2 is expressed on a subset of primary afferent neurons and involved in inflammatory nociception. Transient receptor potential vanilloid subfamily 1 (TRPV1) is a sensory neuron-specific cation channel that responds to capsaicin, protons, or heat stimulus. Here, we show that TRPV1 is coexpressed with PAR2 but not with PAR1 or PAR3, and that TRPV1 can functionally interact with PAR2. In human embryonic kidney 293 cells expressing TRPV1 and PAR2, PAR2 agonists increased capsaicinor proton-evoked TRPV1 currents through a PKC-dependent pathway. After application of PAR2 agonists, temperature threshold for TRPV1 activation was reduced from $42^{\circ} \mathrm{C}$ to well below the body temperature. PAR2-mediated Fos expression in spinal cord was decreased in TRPV1-deficient mice. The functional interaction was also observed in mouse DRG neurons and proved at a behavioral level. These represent a novel mechanism through which trypsin or tryptase released in response to tissue inflammation might trigger the sensation of pain by PAR2 activation.
\end{abstract}

Key words: proteinase-activated receptor; TRPV1; inflammatory pain; PKC; thermal hyperalgesia; mechanical allodynia

\section{Introduction}

Proteinase-activated receptors (PARs) are a subfamily of G-protein-coupled receptors that share a unique mechanism of activation. Molecular cloning has identified four PARs, PAR1PAR4 (Vu et al., 1991; Nystedt et al., 1994; Ishihara et al., 1997; Molino et al., 1997; Kahn et al., 1998). Certain proteinases are known to cleave PARs within the extracellular amino terminus to expose a tethered ligand domain that binds and activates the cleaved receptors (Dery et al., 1998; Hollenberg, 1999). For three of the PARs (PAR1, PAR2, and PAR4), short synthetic peptides have been shown to activate the receptors without unmasking the tethered ligand (Hollenberg and Compton, 2002). PARs are known to play important roles in response to tissue injury, notably in the process of inflammation and repair (Dery et al., 1998). In particular, agonists of PAR2, tryptase, and trypsin released from different cell types, including mast cells, have widespread proinflammatory effects (Saifeddine et al., 1996; Vergnolle et al., 1999, 2001a; Seeliger et al., 2003), in part via a neurogenic mech-

Received Feb. 9, 2004; revised March 18, 2004; accepted March 18, 2004.

This work was supported by grants from the Ministry of Education, Culture, Sports, Science, and Technology in Japan to M.T. and K.N. and by the Japan Brain Foundation, an AstraZeneca Research grant, and Uehara Memorial Foundation to M.T. We thank D. Julius (University of California, San Francisco, CA) for giving us TRPV1-deficient mice

Correspondence should be addressed to M. Tominaga, Department of Cellular and Molecular Physiology, Mie University School of Medicine, Tsu, Mie 514-8507, Japan. E-mail: tominaga@doc.medic.mie-u.ac.jp.

DOI:10.1523/JNEUROSCI.0454-04.2004

Copyright $\odot 2004$ Society for Neuroscience $\quad$ 0270-6474/04/244293-07\$15.00/0 anism (Steinhoff et al., 2000). PAR2 is expressed on a subset of primary sensory neurons, and PAR2 agonists stimulate release of substance $\mathrm{P}(\mathrm{SP})$ and calcitonin gene-related peptide (CGRP) in peripheral tissues (Steinhoff et al., 2000). Furthermore, it has been reported that PAR2 activation can sensitize adult rat dorsal root ganglion (DRG) neurons in vitro and may contribute to the pathogenesis of pain in the pancreas, an organ in which inflammation results in activation of endogenous proteases such as trypsin (Hoogerwerf et al., 2001). In addition to its neurogenic inflammatory effects, intraplantar injection of subinflammatory doses of PAR2 agonists in rat and mice induced a prolonged thermal and mechanical hyperalgesia and elevated spinal Fos protein expression, indicating a direct role for PAR2 in pain transmission (Vergnolle et al., 2001b).

The capsaicin receptor, transient receptor potential vanilloid subfamily 1 (TRPV1), a member of TRP ion channel super family, is a nonselective cation channel expressed predominantly in unmyelinated C-fibers (Julius and Basbaum, 2001). TRPV1 is activated not only by capsaicin but also by protons or heat (with a thermal threshold $>43^{\circ} \mathrm{C}$ ), both of which cause pain in vivo (Caterina et al., 1997; Tominaga et al., 1998; Caterina and Julius, 2001). Recently, we reported that TRPV1 activity was potentiated or sensitized by two inflammatory mediators, ATP and bradykinin, in a PKC-dependent manner (Tominaga et al., 2001; Sugiura et al., 2002) and identified two target serine residues in TRPV1 as substrates for PKC-dependent phosphorylation (Numazaki et 
al., 2002). Considering that a signaling pathway for PAR2 involves the activation of phospholipase $C$ via $G_{q / 11}$-proteins, we hypothesized that a PAR2-mediated mechanism may lead to TRPV1 sensitization in primary sensory DRG neurons and hence contribute to the pathogenesis of thermal and chemical hyperalgesia. We observed significant coexpression of TRPV1 with PAR2 receptors in DRG neurons and found the functional interaction between PAR2 and TRPV1 both in human embryonic kidney (HEK) 293 cells expressing TRPV1 and PAR2 and in mouse DRG neurons, which was confirmed at a behavioral level.

\section{Materials and Methods}

Mammalian cell culture. Human embryonic kidney-derived HEK293 cells were maintained in DMEM (supplemented with 10\% FBS/ penicillin/streptomycin/L-glutamine) and transfected with $1 \mu \mathrm{g}$ of plasmid DNA by using Lipofectamine Plus reagent (Invitrogen, Carlsbad, CA). TRPV1 cDNA was prepared as described previously (Caterina et al., 1997). Although PAR2 is reported to be expressed endogenously at low level in HEK293 cells (Yu et al., 1997), PAR2 cDNA was transfected into HEK293 cells to determine the significance of PAR2 expression. For PAR2 subcloning, on the basis of the previously determined rat PAR2 sequence (Saifeddine et al., 1996) and according to our previous work (Hashimoto et al., 2001; Moriyama et al., 2003), PAR2 cDNA was prepared and ligated into the pTARGET mammalian expression vector (Promega, Madison, WI). Primary cultures of DRG neurons prepared from male adult C57BL/6 strain (wild type; 20 gm body weight; Japan SLC, Shizuoka, Japan) were incubated in medium containing nerve growth factor (100 ng/ml; Sigma, St. Louis, MO).

Electrophysiology. Whole-cell patch-clamp recordings were performed at $1 \mathrm{~d}$ after transfection of rat TRPV1 and rat PAR2 cDNA to HEK293 cells or dissociation of the DRG neurons (Caterina et al., 1997). Standard bath solution contained the following (in $\mathrm{mM}$ ): $140 \mathrm{NaCl}, 5 \mathrm{KCl}, 2 \mathrm{MgCl}_{2}$, 5 EGTA, 10 HEPES, and 10 glucose, pH 7.4 (adjusted with $\mathrm{NaOH}$ ). Bath solution was buffered to $\mathrm{pH} 6.2$ with $10 \mathrm{~mm}$ Mes for examining the proton-evoked current responses. Pipette solution contained the following (in mM): $140 \mathrm{KCl}, 5$ EGTA, and 10 HEPES, pH 7.4 (adjusted with $\mathrm{KOH}$ ). In some experiments, calphostin $\mathrm{C}$ (CalpC) (Calbiochem, La Jolla, CA) or PKC $\epsilon$ translocation inhibitor (Calbiochem) was included in the pipette solution. All patch-clamp experiments were performed at room temperature $\left(25^{\circ} \mathrm{C}\right)$ unless otherwise noted. When examining the heat-evoked current responses, bath temperature was increased by using a preheated solution with the rate of $1.5-2.0^{\circ} \mathrm{C} / \mathrm{sec}(\sim 20 \mathrm{sec})$. When the heat-activated currents started to inactivate, the preheated solution was changed to a $25^{\circ} \mathrm{C}$ solution. Chamber temperature was monitored with a thermocouple (accuracy $\pm 0.1^{\circ} \mathrm{C}$ ) placed within $100 \mu \mathrm{m}$ of the patchclamped cell. The solutions containing drugs were applied to the chamber $(180 \mu \mathrm{l})$ by a gravity at a flow rate of $5 \mathrm{ml} / \mathrm{min}$.

Histochemistry studies. Five rats were perfused transcardially. The L4-L5 DRGs were removed, postfixed, frozen, and cut on a cryostat at an $8 \mu \mathrm{m}$ thickness. Rabbit primary antibody (Ab) for TRPV1 (1:200; Oncogene Research Products, San Diego, CA) and mouse monoclonal Ab for PAR2 (1:100; Santa Cruz Biotechnology, Santa Cruz, CA) combined with Alexa fluor 488 goat anti-rabbit IgG (1:1000; Molecular Probes, Eugene, OR) and Alexa fluor 594 goat anti-mouse IgG (1:1000; Molecular Probes), respectively, were used for double immunofluorescence staining (Dai et al., 2002). For combined TRPV1 immunohistochemistry and PARs mRNA in situ hybridization, immunohistochemistry was performed before in situ hybridization as described previously (Tsuzuki et al., 2001). After DAB staining for TRPV1, sections were processed through hybridization steps as described previously (Moriyama et al., 2003). ${ }^{35}$ S-labeled RNA probes were prepared by in vitro transcription of PAR1 cDNA (GenBank accession number X81642; nucleotides 552-903) and PAR3 cDNA (GenBank accession number AF310076; nucleotides 387-737) fragments in linearized pGEM-T Easy vector (Promega) by using T7 or SP6 RNA polymerase (Promega) and ${ }^{35}$ S-UTP (PerkinElmer Life Sciences, Natick, MA), giving a specific activity of $1.0-1.5 \times 10^{9}$. Quantification of the labeled neurons was performed using randomly selected tissue profiles with bright-field illumination for DAB-stained neurons or dark-field illumination for silver grains over ${ }^{35} \mathrm{~S}$-labeled neurons (Moriyama et al., 2003). At least 250 neurons from an L5 DRG section of each of five rats were measured.

Fos expression. For c-Fos protein immunohistochemistry, six C57BL/6 wild-type and TRPV1-deficient mice were used (both in 25 gm body weight). Two hours after unilateral intraplantar injection of $\mathrm{H}$-Ser-LeuIle-Gly-Arg-Leu- $\mathrm{NH}_{2}\left(\mathrm{SL}-\mathrm{NH}_{2}\right)(10 \mu \mathrm{g}$ in $20 \mu \mathrm{l}$ of saline), mice were deeply anesthetized with sodium pentobarbital $(100 \mathrm{mg} / \mathrm{kg}$, i.p. $)$ and perfused transcardially with $1 \%$ paraformaldehyde in $0.1 \mathrm{M}$ phosphate buffer $(\mathrm{PB})$ followed by $4 \%$ paraformaldehyde in $0.1 \mathrm{~m} \mathrm{~PB}, \mathrm{pH}$ 7.4. L4-L5 segments of the spinal cord were removed, postfixed, and cryoprotected in $30 \%$ sucrose in $0.1 \mathrm{M} \mathrm{PB}$. Spinal cord tissues were frozen and cut with a cryostat in frontal sections (30 $\mu \mathrm{m}$ thickness) and then collected in $0.1 \mathrm{M}$ PBS for immunohistochemistry as described previously (Dai et al., 2001). Rabbit primary Ab for c-Fos (1:10000; Ab-5; Oncogene) was used. The number of Fos-labeled neurons in laminas I-II was counted in randomly selected sections ( $8-10$ sections per mouse).

Behavioral studies. Twelve male TRPV1-deficient mice and twentyfour male $\mathrm{C} 57 \mathrm{BL} / 6$ strain mice back-crossed for five generations (both in 25 gm body weight) were used for behavioral analyses. After adaptation, SL-NH $\mathrm{NH}_{2}(10 \mu \mathrm{g}$ in $20 \mu \mathrm{l})$ or H-Leu-Arg-Gly-Ile-Leu-Ser- $\mathrm{NH}_{2}\left(\mathrm{LR}-\mathrm{NH}_{2}\right)$ $(10 \mu \mathrm{g}$ in $20 \mu \mathrm{l})$ was injected intraplantarly into one hindpaw of each mouse. For thermal hyperalgesia analysis, the response latencies to a radiant paw heating were measured as described previously (Caterina et al., 2000). The heat stimulus was terminated with a withdrawal response or at $20 \mathrm{sec}$ to avoid skin damage. Two latencies were recorded and averaged for the ipsilateral hindpaw in each test session. For mechanical allodynia, 50\% threshold was assessed with calibrated von Frey filaments using an up-down paradigm (Chaplan et al., 1994; Dai et al., 2002). Briefly, six animals in each group were placed in plastic cages with a wire mesh floor, and the von Frey filaments were applied to the mid-plantar surface for $8 \mathrm{sec}$ or until a withdrawal response occurred. Testing was initiated with the $0.6 \mathrm{gm}$ intensity of filament, and the cutoffs of the 0.04 and $4 \mathrm{gm}$ intensities of filament were selected as the low and high limits for testing, respectively. Behavioral tests were performed at five time points (before injection and 10, 30, 60, and 120 min after injection). An assistant, who was unaware of the treatment group, performed all testing. All procedures involving the care and use of mice were performed in accordance with institutional (Mie University) guidelines and the National Institutes of Health Guide for the Care and Use of Laboratory Animals.

Statistical analysis. All results are expressed as mean \pm SEM. An unpaired $t$ test was used to compare electrophysiological data between each of the two groups. ANOVA and two-way, repeated-measurements ANOVA followed by Fisher's PLSD were applied to the c-Fos count data and behavioral data, respectively. A difference was accepted as significant if the probability was $<5 \%(p<0.05)$.

\section{Results}

\section{Coexpression of TRPV1 with PAR2 in DRG neurons}

To identify whether PARs express in DRG neurons and colocalize with TRPV1, we performed double immunohistochemistry for PAR2 and TRPV1. Because of the lack of available antibodies against PAR1 and PAR3, in situ hybridization for PAR1 or PAR3 mRNA combined with immunohistochemistry for TRPV1 was used. Because we could detect only tiny signals for PAR4 mRNA (data not shown), we decided not to examine the interaction between TRPV1 and PAR4 receptors. We detected PAR2-like immunoreactivity (PAR2-LI) in many small-sized and some medium- to large-sized DRG neurons (Fig. $1 A$ ), whereas TRPV1 was expressed primarily in small DRG neurons (Fig. $1 B$ ), consistent with the previous studies (Caterina et al., 1997; Tominaga et al., 1998; Steinhoff et al., 2000). We found a significant population of TRPV1-labeled neurons that also showed PAR2-LI. TRPV1-expressing neurons $(88.6 \pm 2.9 \%)$ were PAR2-LI positive (Fig. $1 C, F$ ), whereas $62.6 \pm 3.1 \%$ of PAR2-expressing neurons were labeled with anti-TRPV1 $\mathrm{Ab}$. In contrast to the high 
A

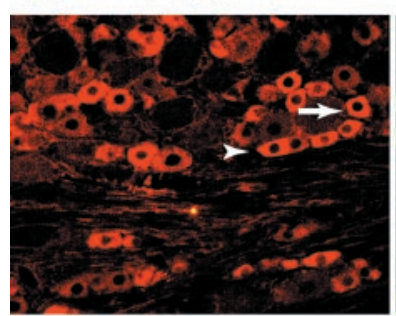

B

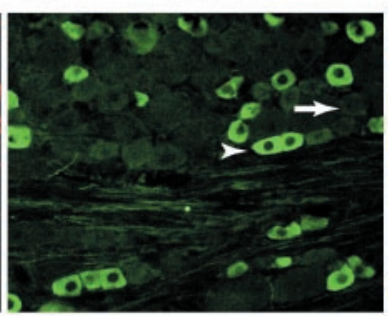

E

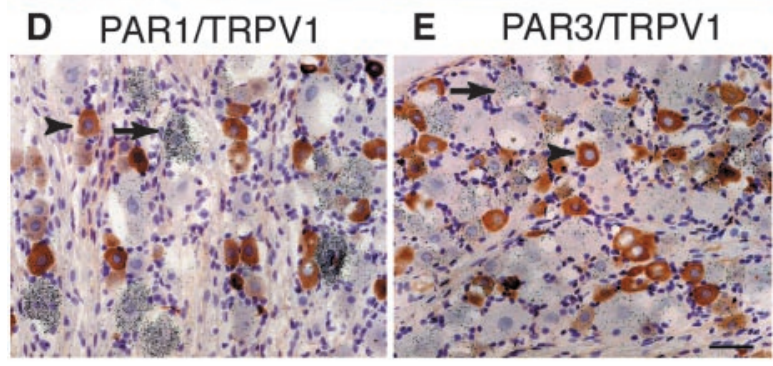

C Merged

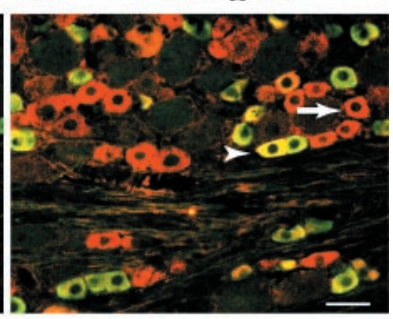

$\mathbf{F}$

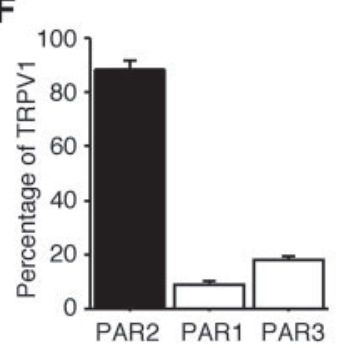

Figure 1. PAR2, but not PAR1 and PAR3, coexpressed with TRPV1 in rat DRG neurons. $A-C$, Microphotographs show localization of PAR2 with TRPV1 by immunofluorescence. A, Detection of PAR2-LI (red) in many small-sized and some medium- to large-sized neurons. B, TRPV1-LI (green) in small-sized neurons. C, Colocalization with TRPV1 and PAR2 in DRG neurons. Merged, Yellow. Arrowheads represent neurons expressing both TRPV1 and PAR2, and arrows represent neurons expressing PAR2 but not TRPV1. D, E, Colocalization of TRPV1 protein with PAR1 (D) or PAR3 (E) mRNA. In situ hybridization histochemistry of PARs, using ${ }^{35}$ S-labeled antisense probes and visualized as clusters of silver grains, was combined with immunohistochemistry of TRPV1 by using DAB staining method. Arrowheads represent neurons expressing TRPV1 but not PARs, and arrows represent neurons expressing PARs but not TRPV1. F, Percentage of neurons expressing PARs in TRPV1-positive ones. Scale bars, $50 \mu \mathrm{m}$.

incidence of colocalization of TRPV1 with PAR2, we rarely detected colocalization of PAR1 or PAR3 mRNA and TRPV1 immunoreactivity (Fig. 1D-F). This high percentage of coexpression of TRPV1 with PAR2 in DRG neurons indicates a possible interaction between them in primary afferent neurons.

\section{Functional interaction between TRPV1 and PAR2 in HEK293 cells expressing TRPV1 and PAR2}

To determine the interaction of TRPV1 with PAR2, we examined the effects of a synthetic-selective active peptide for PAR2, SL$\mathrm{NH}_{2}$ on the capsaicin-activated currents in HEK293 cells expressing rat TRPV1 and rat PAR2 using a whole-cell patch-clamp technique. In voltage-clamp experiments, low doses of capsaicin ( 10 or $20 \mathrm{nM}$ ) evoked small inward currents in the HEK293 cells. In the absence of extracellular $\mathrm{Ca}^{2+}$, no change was observed in the magnitude of responses evoked by repetitive capsaicin applications (Fig. 2C, Cont.). After 2 min pretreatment with $100 \mu \mathrm{M}$ $\mathrm{SL}-\mathrm{NH}_{2}$, the same doses of capsaicin produced much larger current responses $\left(6.64 \pm 1.46\right.$-fold, $n=14$ for $\mathrm{SL}_{-} \mathrm{NH}_{2} ; 0.98 \pm$ 0.07 -fold, $n=5$ for control; $p<0.05$ ) (Fig. $2 A-C$ ), and no such potentiation was detected in cells pretreated with the reversed control peptide, $\mathrm{LR}_{-} \mathrm{NH}_{2}(1.00 \pm 0.06$-fold; $n=5 ; p<0.05$ vs $\mathrm{SL}-\mathrm{NH}_{2}$ ) (Fig. $2 \mathrm{C}$ ). To investigate the time course of the SL-NH effect, we applied capsaicin (20 nM) 0.5, 3, and 7 min after SL$\mathrm{NH}_{2}$ treatment. The potentiating effect of SL- $\mathrm{NH}_{2}$ persisted for several minutes after removal of $\mathrm{SL}-\mathrm{NH}_{2}$ from the bath, suggesting the involvement of cytosolic second messengers in this process (Fig. 2A,B). Other electrophysiological properties of these capsaicin-evoked responses, including an outwardly rectifying current-voltage relationship, antagonist (capsazepine) sensitivity, and extracellular $\mathrm{Ca}^{2+}$-dependent desensitization, were unchanged by the presence of SL- $\mathrm{NH}_{2}$ (data not shown). To examine how $\mathrm{SL}-\mathrm{NH}_{2}$ changes TRPV1 responsiveness, we measured TRPV1 currents in single cells by serially applying a range of concentration of capsaicin in the absence or presence of SL-NH $\mathrm{N}_{2}$. The currents were normalized to the maximal current without SL-NH$H_{2}$ to each cell. Maximal currents in the presence of SL- $\mathrm{NH}_{2}$ were almost the same as those obtained in the absence of $\mathrm{SL}-\mathrm{NH}_{2}$. The resultant dose-response curves clearly demonstrate that PAR2 activation enhances TRPV1 responsiveness on TRPV1 by lowering $\mathrm{EC}_{50}$ values without altering maximal responses $\left(\mathrm{EC}_{50}\right.$ from 153 to $100 \mathrm{~nm}$ ) (Fig. 2 D). A similar potentiating effect of SL- $\mathrm{NH}_{2}$ was observed on proton-evoked activation of TRPV1 ( $1.00 \pm 0.09$-fold, $n=5$ for control; $0.95 \pm 0.11$-fold, $n=5$ for LR-NH $\mathrm{NH}_{2}$; $4.66 \pm 1.05$-fold, $n=7$ for SL-NH $\mathrm{NH}_{2} ;<$ 0.05 vs control and $\mathrm{LR}-\mathrm{NH}_{2}$ ) (Fig. $2 E, F$ ), suggesting that potentiation of TRPV1 by $\mathrm{SL}-\mathrm{NH}_{2}$ was not ligand specific.

Potentiating effects of PAR2 activation were also examined on the heat-evoked responses in HEK293 cells expressing TRPV1 and PAR2. For this analysis, heatevoked current responses were compared between different cells rather than within the same cell, because repetitive heatevoked currents show significant desensitization even in the absence of extracellular $\mathrm{Ca}^{2+}$ (Tominaga et al., 1998). Without pretreatment of SL$\mathrm{NH}_{2}$, heat-evoked currents on HEK293 cells coexpressing TRPV1 and PAR2 developed at $41.6 \pm 0.5^{\circ} \mathrm{C}(n=15)$ with an extremely steep temperature dependence (Fig. $3 A, C$ ). In contrast, pretreatment with $\mathrm{SL}-\mathrm{NH}_{2}$ at a concentration as low as 1 $\mu \mathrm{M}$ significantly lowered the threshold temperature for TRPV1 activation to $30.8 \pm 2.5^{\circ} \mathrm{C}\left[n=12 ; p<0.05\right.$ vs SL-NH $\left.\mathrm{NH}_{2}(-)\right]$ (Fig. $3 B, C)$. The threshold temperature for TRPV1 activation was significantly reduced even at $10 \mathrm{~min}$ after removal of $\mathrm{SL}-\mathrm{NH}_{2}$ when heat stimulus was applied $0.5,3,7$, and $10 \mathrm{~min}$ after SL- $\mathrm{NH}_{2}$ treatment $\left[32.0 \pm 3.8^{\circ} \mathrm{C} ; n=7 ; p<0.05\right.$ vs SL-NH$\left.H_{2}(-)\right]$ (Fig. $3 C)$. This long-lasting effect on the threshold temperature apparently seems to be different from the effect on the capsaicinevoked current responses. However, it is known that the thermal sensitivity of TRPV1 increased with repeated heat applications without any additional treatment in the oocytes system (Caterina et al., 1999), indicating that persisted reduction of the threshold temperature after $\mathrm{SL}-\mathrm{NH}_{2}$ treatment might be attributable to sensitization by repeated heat stimuli. These data clearly show that TRPV1 currents evoked by any of three different stimuli (capsaicin, proton, or heat) are potentiated or sensitized by PAR2 activation.

The signaling pathway in the downstream of PAR2 for sensitization of TRPV1 remains to be clarified. We recently reported that $\mathrm{G}_{\mathrm{q} / 11}$-coupled metabotropic receptor activation such as ATP (P2Y) and bradykinin (B2) receptors causes potentiation or sensitization of TRPV1 through the PKC-dependent phosphorylation of TRPV1 (Tominaga et al., 2001; Sugiura et al., 2002; Moriyama et al., 2003). Therefore, we examined whether a similar signal transduction pathway is involved in the regulation of TRPV1 responses through PAR2, a member of the $\mathrm{G}_{\mathrm{q} / 11}$-coupled metabotropic receptor family. When CalpC, a highly potent and specific $\mathrm{PKC}$ inhibitor was included in the pipette solution, the effect of SL- $\mathrm{NH}_{2}$ was almost completely inhibited $(0.93 \pm 0.08$ - 
fold; $n=6 ; p<0.05$ vs SL-NH ${ }_{2}$ ) (Fig. $2 C$ ). Similarly, a PKC $\epsilon$ translocation inhibitor (PKC $\epsilon-\mathrm{I})$ abolished the potentiation of TRPV1 response by SL- $\mathrm{NH}_{2}(1.02 \pm 0.12$ fold; $n=6 ; p<0.05$ vs SL-NH ${ }_{2}$ ) (Fig. $2 C$ ). These data suggest that SL- $\mathrm{NH}_{2}$-induced potentiation of TRPV1 responsiveness develops through activation of PKC $\epsilon$. To further confirm the involvement of PKC-dependent phosphorylation, effects of PAR2 activation were examined using cells expressing a TRPV1 mutant, S502A/S800A, that is insensitive to PKCdependent phosphorylation (Numazaki et al., 2002). No potentiations of capsaicin-activated currents were observed after $\mathrm{SL}-\mathrm{NH}_{2}$ treatment of cells expressing S502A/S800A (1.01 \pm 0.04-fold; $n=6$; $p<0.05$ vs SL- $\mathrm{NH}_{2}$ ) (Fig. $2 \mathrm{C}$ ), further indicating the involvement of PKCdependent phosphorylation.

\section{Functional interaction between TRPV1} and PAR2 in mouse DRG neurons

Cell types differ in their membrane lipid composition, and we asked whether PAR2 activation would also sensitize TRPV1 channels with the same PKC-dependent mechanism in sensory neurons. We performed voltage-clamp experiments in mouse DRG neurons cultured without any proteinase treatment. In capsaicin-responsive neurons, as in HEK293 cells expressing TRPV1 and PAR2, we found that SL- $\mathrm{NH}_{2}$ but not LR$\mathrm{NH}_{2}$ significantly increased the capsaicinevoked currents $(0.83 \pm 0.09$-fold, $n=8$ for control; $0.89 \pm 0.07$-fold, $n=6$ for $\mathrm{LR}_{-} \mathrm{NH}_{2}$; $4.11 \pm 1.22$-fold, $n=6$ for SL-NH $\mathrm{NH}_{2} ; p<0.01$ vs control and $\mathrm{LR}-\mathrm{NH}_{2}$ ) (Fig. $4 A, D$ ). As possible physiological ligands of PAR2 receptor, trypsin and mast cell tryptase can cleave PAR2 within the extracellular N-terminal domains and then activate the cleaved receptor. Like SL- $\mathrm{NH}_{2}$, both trypsin and tryptase application to the cultured DRG neurons also significantly potentiated the capsaicin-induced currents $(5.65 \pm 2.41$-fold, $n=5$ for trypsin, $p<0.05$ vs control; $4.30 \pm 0.83$-fold, $n=5$ for tryptase, $p<$ 0.01 vs control) (Fig. $4 B-D$ ). To confirm the involvement of PKCdependent events in the downstream of PAR2 activation, we examined the effects of CalpC and PKC $\epsilon$-I in DRG neurons. Similar to that observed in HEK293 cells, SL- $\mathrm{NH}_{2}$ or trypsin failed to potentiate the capsaicin-activated currents when CalpC or PKC $\epsilon$-I was included in the pipette solution (Fig. 4D).

PAR2 activation causes thermal hyperalgesia and mechanical allodynia depending on TRPV1 expression

Intraplantar injection of $10 \mu \mathrm{g}$ of SL- $\mathrm{NH}_{2}$ has been reported to cause both pronounced thermal hyperalgesia and mechanical allodynia, but neither induced edema or granulocyte infiltration nor elicited any change in blood flow in the paw (Vergnolle et al., 2001b). Therefore, we investigated the involvement of TRPV1 in PAR2 agonist-induced thermal hyperalgesia and mechanical allodynia at a behavioral level. Intraplantar administration of $10 \mu \mathrm{g}$ of SL-NH$H_{2}$ but not $\mathrm{LR}-\mathrm{NH}_{2}$ produced a significant reduction in
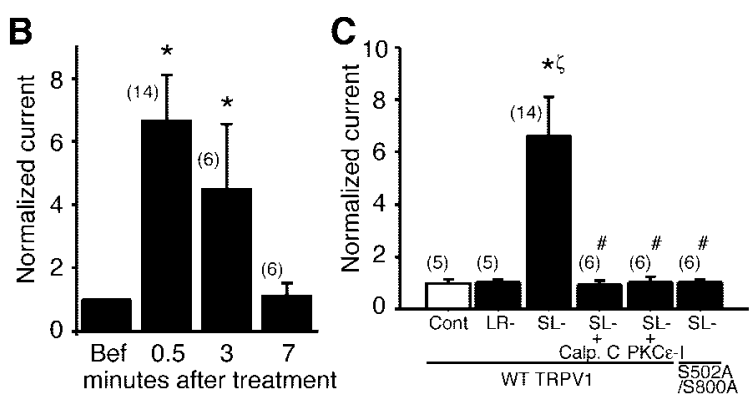

E

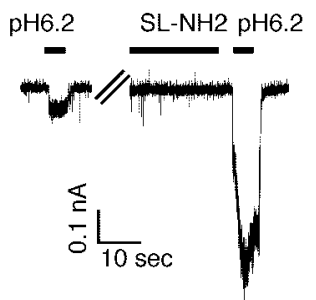

$F$

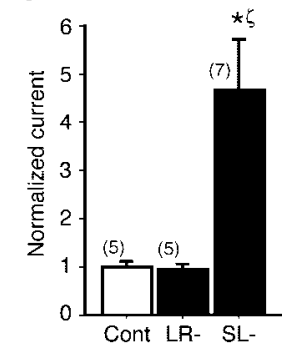

Figure 2. The PAR2 agonist SL-NH 2 potentiates or sensitizes capsaicin- and proton-activated currents in a PKC-dependent manner in HEK293 cells. A, A representative trace of increase of capsaicin (Cap, 20 nm)-activated current in transfected HEK293 cells expressing rat TRPV1 and rat PAR2. Cells were perfused for 2 min with solution containing SL- $\mathrm{NH}_{2}(100 \mu \mathrm{m})$ before capsaicin cont; ${ }^{\zeta} p<0.05$ versus LR-NH ${ }_{2}{ }^{*} p<0.05$ versus SL-NH 2 ; unpaired $t$ test. $D$, Capsaicin dose-response curves for TRPV1 activation in the absence $(O)$ and presence $(\bigcirc)$ of $100 \mu \mathrm{m} \mathrm{SL-NH}$. Currents were normalized to the currents maximally activated by $1 \mu \mathrm{M}$

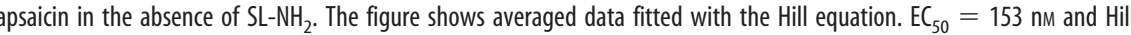
obtained from 32 different cells. $\mathrm{F}$ A representative trace of increase of proton (pH 6.2)-activated current in transfected $\mathrm{HEK} 293$ cells expressing TRPV1 and PAR2. F, SL-NH but not LR-NH 2 potentiates proton-evoked TRPV1 responses. $V_{\mathrm{h}}=-60 \mathrm{mV}$. Currents were normalized to values induced by first proton application in the absence of SL- $\mathrm{NH}_{2}$ or $\mathrm{LR}-\mathrm{NH}_{2}$. Numbers in parentheses indicate cells tested. ${ }^{*} p<0.05$ versus Cont; ${ }^{\zeta} p<0.05$ versus $\mathrm{LR}^{\mathrm{N}} \mathrm{NH}$; ; unpaired $t$ test.

paw withdrawal latency in response to radiant heat (thermal hyperalgesia) and von Frey filaments (mechanical allodynia) at $10-$ $120 \mathrm{~min}$ in wild-type mice (Fig. $5 \mathrm{~A}, \mathrm{~B}$ ). In contrast, the SL- $\mathrm{NH}_{2}$ induced thermal hyperalgesia was significantly attenuated in TRPV $1^{-1-}$ mice (Fig. 5A). Surprisingly, SL-NH ${ }_{2}$-induced mechanical allodynia was also significantly attenuated at the time point of $120 \mathrm{~min}$ after injection in TRPV1 ${ }^{-/-}$mice (Fig. $5 B$ ). Because TRPV1 was not suggested to be involved in mechanical sensation (Caterina et al., 2000), the inhibition of mechanical allodynia might be attributable to the central sensitization caused by $\mathrm{SL}-\mathrm{NH}_{2}$-induced primary afferent hypersensitivity. To examine the alteration of activity in dorsal horn neurons, we examined SL- $\mathrm{NH}_{2}$-induced spinal Fos expression in wild-type and TRPV1 ${ }^{-1-}$ mice (Hunt et al., 1987). The number of Fos-LI nuclei in laminas I-II per section of spinal dorsal horn at the L4-L5 level was significantly increased after intraplantar injection of $10 \mu \mathrm{g}$ of SL- $\mathrm{NH}_{2}$ but not LR-NH $\mathrm{NH}_{2}$ in wild-type mice (Fig. 6A,B). We found a significant reduction of Fos expression caused by the same agonist administration in TRPV1 ${ }^{-1-}$ mice (Fig. $6 C, D$ ), indicating that the increased activity of dorsal horn neurons was attenuated in TRPV $1^{-1-}$ mice after SL- $\mathrm{NH}_{2}$ application to the peripheral tissue. 

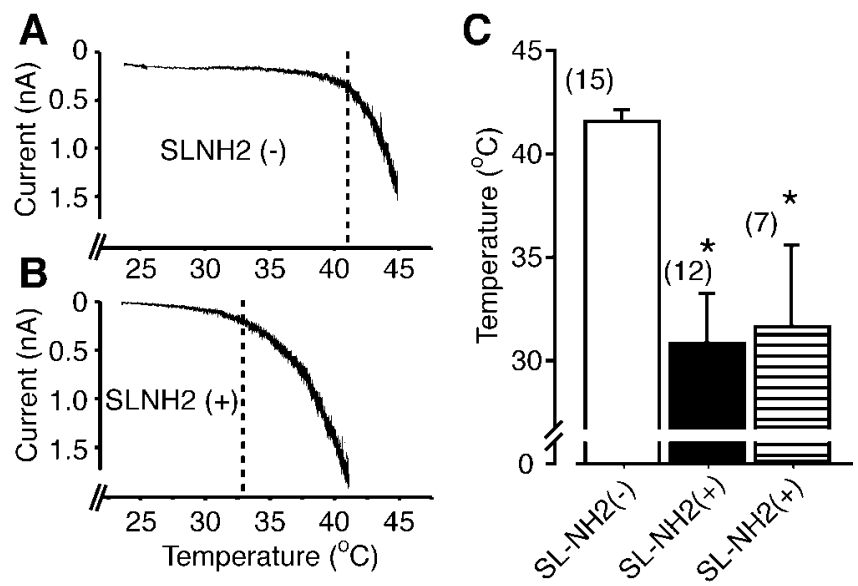

Figure 3. Temperature threshold for TRPV1 activation was reduced in the presence of SL$\mathrm{NH}_{2}$ in HEK293 cells. $A, B$, Representative temperature-response profiles of heat-activated currents in the absence $(A)$ and presence $(B)$ of $S L-\mathrm{NH}_{2}(100 \mu \mathrm{M})$. Dashed lines show the threshold temperature for heat activation of TRPV1. $V_{\mathrm{h}}=-60 \mathrm{mV}$. C, Temperature thresholds for TRPV1 activation in the presence of $S L-\mathrm{NH}_{2}\left(\right.$ black bar) $\left(30.8 \pm 2.5^{\circ} \mathrm{C} ; n=12\right)$ and 10 min after SL-NH treatment (hatched bar) $\left(32.0 \pm 3.8^{\circ} \mathrm{C} ; n=7\right)$ were significantly lower than that in the absence of SL-NH $2\left(41.6 \pm 0.5^{\circ} \mathrm{C} ; n=15\right)$. Temperature ramp was applied $0.5,3,7$, and $10 \mathrm{~min}$ after $\mathrm{SL}_{-} \mathrm{NH}_{2}$ treatment. Numbers in parentheses indicate cells tested. ${ }^{*} p<0.05$ versus $\mathrm{SL}-\mathrm{NH}_{2}$ $(-)$; unpaired $t$ test. Threshold was defined as a temperature at which clear current increase was observed in the temperature-response profile.
A
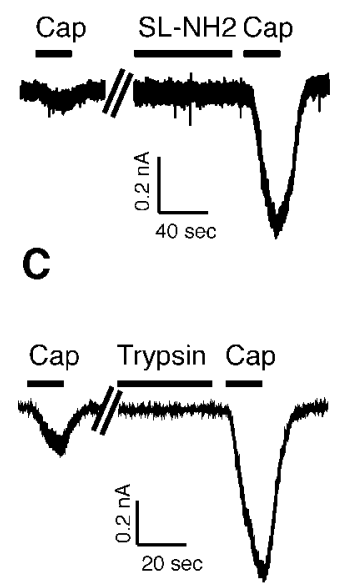

B
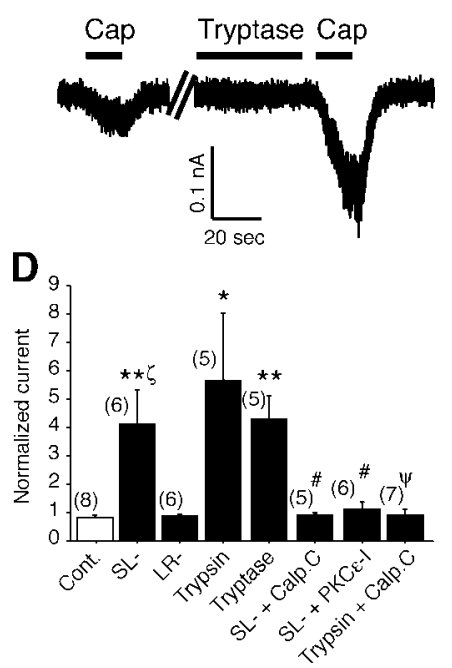

Figure 4. PAR2 agonists potentiate capsaicin-activated currents in mouse DRG neurons. $A-C$, Representative traces of increase of the capsaicin (Cap, $100 \mathrm{~nm}$ )-activated currents by SL-NH $2(100 \mu \mathrm{M})(A)$, tryptase $(100 \mathrm{~nm})(B)$, or trypsin $(50 \mathrm{~nm})(C) . V_{\mathrm{h}}=-60 \mathrm{mV}$. D, Effects of PAR2 agonists and PKC inhibitors on the capsaicin-activated currents. Currents were normalized to the currents evoked initially by capsaicin in the absence of the additives. Capsaicin was reapplied 2 min after exposure to these solutions. In some experiments, calphostin C (Calp. C) at $1 \mu \mathrm{m}$ or PKC $\epsilon$ translocation inhibitor (PKC $\epsilon-\mathrm{I})$ at $200 \mu \mathrm{m}$ was included in the pipette solution. Cont, Control group (preperfused with bath solution without any additives before reapplication of capsaicin); $\mathrm{LR}-, \mathrm{LR}-\mathrm{NH}_{2} ; \mathrm{SL}-, \mathrm{SL}-\mathrm{NH}_{2}$. Numbers in parentheses indicate cells tested. ${ }^{*} p<$ 0.05 ; ${ }^{* *} p<0.01$ versus Cont.; ${ }^{\zeta} p<0.05$ versus LR-NH ${ }_{2}{ }^{*} p<0.05$ versus SL-NH ${ }_{2} ;{ }^{*} p<0.05$ versus trypsin; unpaired $t$ test.

\section{Discussion}

Inflammatory pain is initiated by tissue damage-inflammation and is characterized by hypersensitivity both at the site of damage and in adjacent tissue. In the context of inflammation, stimuli that normally would not produce pain do so (allodynia), whereas
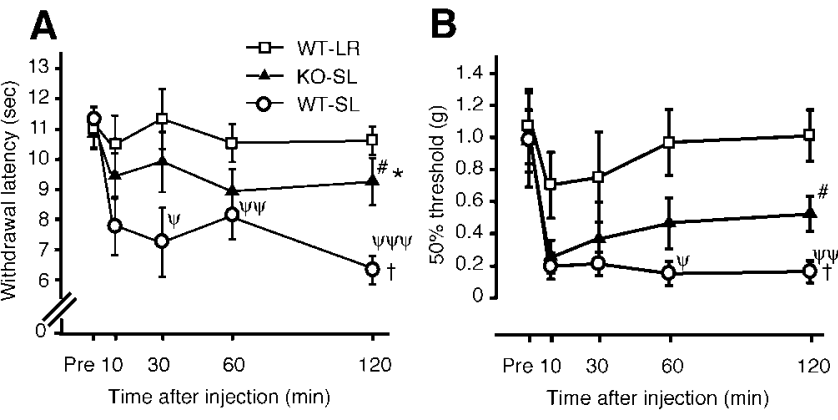

Figure 5. SL-NH ${ }_{2}$-induced thermal hyperalgesia and mechanical allodynia were attenuated in TRPV1-deficient mice. $A, B$, Reduction of paw withdrawal latency to radiant lamp $(A)$ and $50 \%$ paw withdrawal threshold to von Frey filaments $(B)$ by intraplantar injection of $\mathrm{SL}-\mathrm{NH}_{2}(10$ $\mu \mathrm{g}$ per paw) was significantly attenuated in TRPV1-deficient mice (KO-SL). ${ }^{*} p<0.05$ versus wild-type mice treated with $\mathrm{SL}_{-} \mathrm{NH}_{2}$ (WT-SL); two-way repeated ANOVA followed by Fisher's PLSD; ${ }^{\#} p<0.05$ versus WT-SL; unpaired $t$ test $;{ }^{\dagger} p<0.05$ versus wild-type mice treated with LR-NH ${ }_{2}\left(10 \mu \mathrm{g}\right.$ per paw) (WT-LR); two-way repeated ANOVA followed by Fisher's PLSD. ${ }^{*} p<$ $0.05 ;{ }^{\psi *} \psi p<0.001 ;{ }^{* \psi \psi} p<0.0001$ versus WT-SL; unpaired $t$ test; $n=6$ per group.
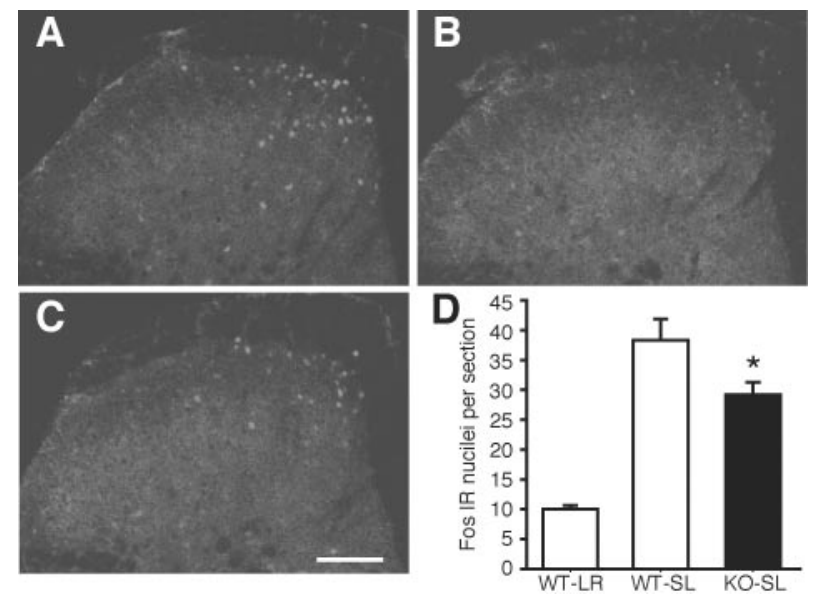

Figure 6. PAR2 agonist-induced Fos expression in dorsal horn is significantly reduced in TRPV1-deficient mice. $A-C$, Microphotographs show Fos expression in dorsal horn nuclei of wild-type mice with intraplantar injection of SL-NH $\mathrm{N}_{2}(10 \mu \mathrm{g}$ per paw) (WT-SL) ( $A$ ) or LR-NH (10 $\mu$ g per paw) (WT-LR) (B), or TRPV1-deficient mice with intraplantar injection of SL- $\mathrm{NH}_{2}(10$ $\mu$ g per paw) (KO-SL) (C). D, Quantitative changes in Fos-LI in lamina I-II neurons of $L 4$ and $L 5$ dorsal horn after injection in WT-SL, W-LR, and KO-SL; $n=6$ per group; ${ }^{*} p<0.05$ versus WT-SL. Scale bar, $100 \mu \mathrm{m}$.

previously noxious stimuli evoke even greater pain responses (hyperalgesia). One mechanism underlying these phenomena is the modulation (sensitization) of ion channels, such as TRPV1, that detect noxious stimuli at the nociceptor terminal (Mizumura and Kumazawa, 1996; Wood and Perl, 1999; Woolf and Salter, 2000; Tominaga et al., 2001). Mediators known to cause sensitization of TRPV1 include bradykinin and ATP (Premkumar and Ahern, 2000; Chuang et al., 2001; Tominaga et al., 2001; Sugiura et al., 2002). In the present study, we observed that PAR2 activated by mast cell tryptase or trypsin in vivo could lead to an increase in afferent signaling via TRPV1 sensitization, which in turn may cause sensitization at the spinal cord level, resulting in amplification and persistence of pain sensation. Our results support the previous reports that PAR2 agonists enhanced capsaicinevoked release of CGRP in isolated DRG neurons (Hoogerwerf et al., 2001).

In recent years, a novel nociceptive pathway mediated by PAR2 has received much attention (Steinhoff et al., 2000; Hoogerwerf et al., 2001; Vergnolle et al., 2001b). Proteinases and 
PAR2 are known to cause hyperalgesia in response to both thermal and mechanical stimuli (Hoogerwerf et al., 2001; Vergnolle et al., 2001b). However, the underlying mechanism of PAR2mediated hyperalgesia has not been fully manifested, although involvement of TRPV1 has been suggested (Hoogerwerf et al., 2001; McLean et al., 2002). PAR2 agonists have been thought to cause signal transmission to second afferent neurons by inducing release of neuropeptides from the central terminal of primary afferents and causing Fos expression in superficial spinal neurons (Hoogerwerf et al., 2001; Vergnolle et al., 2001b). However, these events cannot occur within the spinal cord without action potential generation in primary afferents. Because PAR2 is a G-proteincoupled receptor, its activation itself is not sufficient to induce action potentials in primary afferents, suggesting that PAR2 can functionally interact with other molecules such as ion channels, thereby causing depolarization. We showed that activation of PAR2 led to sensitization or potentiation of TRPV1 activity. PAR2 agonist reduced temperature threshold for TRPV1 activation in HEK293 cells expressing both PAR2 and TRPV1 from 42 to $32^{\circ} \mathrm{C}$, so that body temperature may activate TRPV 1 in the presence of PAR2 agonists. This might well explain the PAR2 agonist-induced neurotransmitter release (such as SP and CGRP) and Fos expression in spinal cord. Our data presented herein also demonstrate that TRPV1 is highly colocalized with PAR2 in primary sensory neurons and is essential for the development of PAR2 agonist-induced hyperalgesia. This interaction between PAR2 and TRPV1 might be one important underlying mechanism for the PAR2-mediated inflammatory pain. Proinflammatory actions of PAR2 involving nitric oxide, E-selectin, intercellular adhesion molecule-1, and interleuleukin-6 are important for PAR2 agonist-induced neurotransmitter release as well (Seeliger et al., 2003).

In the present study, TRPV1 currents evoked by any of three different stimuli (capsaicin, proton, or heat) are potentiated or sensitized by PAR2 activation. Although activation of PAR2 results in intracellular $\mathrm{Ca}^{2+}$ mobilization (Steinhoff et al., 2000), it is not a likely mechanism for the capsaicin-evoked current increase observed in our experiments, because cytosolic-free $\mathrm{Ca}^{2+}$ is tightly chelated with the $5 \mathrm{~mm}$ EGTA included in the pipette solution. Lack of potentiating effects of PAR2 agonists in cells treated with PKC inhibitors and in cells expressing a TRPV1 mutant lacking substrates for PKC-dependent phosphorylation indicate that PKC-dependent pathway is predominantly involved in PAR2-mediated TRPV1 sensitization. Together with the previous reports suggesting the possible coupling of PAR2 with $\mathrm{G}_{\mathrm{q} / 11}$-protein (Dery et al., 1998), our data indicate that PAR2 involves a PKC-dependent signal transduction pathway in exhibiting its effects.

As an activation maker of the secondary spinal neuron, Fos expression is thought to be induced by stimulation of primary afferents. Intraplantar injection of a PAR2 agonist at a dose below the threshold for eliciting inflammation resulted in a marked increase in Fos expression, indicating that action potentials were generated by PAR2 stimulation. The fact that Fos expression was significantly reduced in mice lacking TRPV1 suggests that TRPV1 is essential for the generation of PAR2 agonist-induced neuronal activation in the spinal cord. However, Fos expression in mice lacking TRPV1 was not completely inhibited, suggesting the existence of other mechanisms in the downstream of PAR2 activation (Seeliger et al., 2003). The result that only $62.6 \%$ of PAR2 expressing neurons in DRG were TRPV1 positive might support the possibility. Mechanical allodynia was significantly attenuated in TRPV1-deficient mice, although TRPV1 has not been thought to be involved in the development of the allodynia (Caterina et al., 2000). The allodynia might develop through sensitization in the spinal cord level, which is distinct from one involving TRPV1 activation observed at periphery.

Tryptase and trypsin, the selective agonists on physiological state for PAR2, could be released from peripheral tissue and visceral organs in inflammatory diseases. Our results represent a novel mechanism through which trypsin or tryptase released in response to tissue inflammation might trigger the sensation of pain by PAR2 activation. Although proteinase inhibitors and PAR2 antagonists seem to be effective for anti-inflammation and anti-nociception, absence of selective PAR2 antagonists and proteinase inhibitors makes it difficult to perform experimental studies in animals or humans. PAR2 is expressed in a wide variety of tissues including lung, liver, kidney, and gastrointestinal tract, where it might be involved in physiological and pathophysiological processes, including mucosal protection and repair (Cocks et al., 1999; Lindner et al., 2000; Reinshagen et al., 2000; Fiorucci et al., 2001; Kawabata et al., 2001). It is therefore possible that blockade of PAR2 could be associated with adverse effects in these tissues. Because our present data demonstrated that PAR2mediated hyperalgesia in animal models primarily depends on TRPV1 receptor, compounds acting on TRPV1 or interfering with the interaction between TRPV1 and PAR2 could prove useful in the treatment of pain. Furthermore, the fact that TRPV1 is one of the main targets of many inflammatory mediators such as bradykinin, ATP, and NGF (Premkumar and Ahern, 2000; Chuang et al., 2001; Tominaga et al., 2001; Sugiura et al., 2002) suggests that TRPV1 may be one best candidate for the development of drugs controlling inflammatory pain.

\section{References}

Caterina MJ, Julius D (2001) The vanilloid receptor: a molecular gateway to the pain pathway. Annu Rev Neurosci 24:487-517.

Caterina MJ, Schumacher MA, Tominaga M, Rosen TA, Levine JD, Julius D (1997) The capsaicin receptor: a heat-activated ion channel in the pain pathway. Nature 389:816-824

Caterina MJ, Rosen TA, Tominaga M, Brake AJ, Julius D (1999) A capsaicin-receptor homologue with a high threshold for noxious heat. Nature 398:436-441.

Caterina MJ, Leffler A, Malmberg AB, Martin WJ, Trafton J, Petersen-Zeitz KR, Koltzenburg M, Basbaum AI, Julius D (2000) Impaired nociception and pain sensation in mice lacking the capsaicin receptor. Science 288:306-313.

Chaplan SR, Bach FW, Pogrel JW, Chung JM, Yaksh TL (1994) Quantitative assessment of tactile allodynia in the rat paw. J Neurosci Methods 53:55-63.

Chuang HH, Prescott ED, Kong H, Shields S, Jordt SE, Basbaum AI, Chao MV, Julius D (2001) Bradykinin and nerve growth factor release the capsaicin receptor from PtdIns(4,5)P2-mediated inhibition. Nature 411:957-962.

Cocks TM, Fong B, Chow JM, Anderson GP, Frauman AG, Goldie RG, Henry PJ, Carr MJ, Hamilton JR, Moffatt JD (1999) A protective role for protease-activated receptors in the airways. Nature 398:156-160.

Dai Y, Iwata K, Kondo E, Morimoto T, Noguchi K (2001) A selective increase in Fos expression in spinal dorsal horn neurons following graded thermal stimulation in rats with experimental mononeuropathy. Pain 90:287-296.

Dai Y, Iwata K, Fukuoka T, Kondo E, Tokunaga A, Yamanaka H, Tachibana T, Liu Y, Noguchi K (2002) Phosphorylation of extracellular signalregulated kinase in primary afferent neurons by noxious stimuli and its involvement in peripheral sensitization. J Neurosci 22:7737-7745.

Dery O, Corvera CU, Steinhoff M, Bunnett NW (1998) Proteinaseactivated receptors: novel mechanisms of signaling by serine proteases. Am J Physiol 274:C1429-C1452.

Fiorucci S, Mencarelli A, Palazzetti B, Distrutti E, Vergnolle N, Hollenberg MD, Wallace JL, Morelli A, Cirino G (2001) Proteinase-activated receptor 2 is an anti-inflammatory signal for colonic lamina propria 
lymphocytes in a mouse model of colitis. Proc Natl Acad Sci USA 98:13936-13941.

Hashimoto N, Yamanaka H, Fukuoka T, Obata K, Mashimo T, Noguchi K (2001) Expression of hepatocyte growth factor in primary sensory neurons of adult rats. Brain Res Mol Brain Res 97:83-88.

Hollenberg MD (1999) Protease-activated receptors: PAR4 and counting: how long is the course? Trends Pharmacol Sci 20:271-273.

Hollenberg MD, Compton SJ (2002) International union of pharmacology. XXVIII. Proteinase-activated receptors. Pharmacol Rev 54:203-217.

Hoogerwerf WA, Zou L, Shenoy M, Sun D, Micci MA, Lee-Hellmich H, Xiao SY, Winston JH, Pasricha PJ (2001) The proteinase-activated receptor 2 is involved in nociception. J Neurosci 21:9036-9042.

Hunt SP, Pini A, Evan G (1987) Induction of c-fos-like protein in spinal cord neurons following sensory stimulation. Nature 328:632-634.

Ishihara H, Connolly AJ, Zeng D, Kahn ML, Zheng YW, Timmons C, Tram T, Coughlin SR (1997) Protease-activated receptor 3 is a second thrombin receptor in humans. Nature 386:502-506.

Julius D, Basbaum AI (2001) Molecular mechanisms of nociception. Nature 413:203-210.

Kahn ML, Zheng YW, Huang W, Bigornia V, Zeng D, Moff S, Farese Jr RV, Tam C, Coughlin SR (1998) A dual thrombin receptor system for platelet activation. Nature 394:690-694.

Kawabata A, Kinoshita M, Nishikawa H, Kuroda R, Nishida M, Araki H, Arizono N, Oda Y, Kakehi K (2001) The protease-activated receptor-2 agonist induces gastric mucus secretion and mucosal cytoprotection. J Clin Invest 107:1443-1450.

Lindner JR, Kahn ML, Coughlin SR, Sambrano GR, Schauble E, Bernstein D, Foy D, Hafezi-Moghadam A, Ley K (2000) Delayed onset of inflammation in protease-activated receptor-2-deficient mice. J Immunol 165:6504-6510.

McLean PG, Aston D, Sarkar D, Ahluwalia A (2002) Protease-activated receptor-2 activation causes EDHF-like coronary vasodilation: selective preservation in ischemia/reperfusion injury: involvement of lipoxygenase products, VR1 receptors, and C-fibers. Circ Res 90:465-472.

Mizumura K, Kumazawa T (1996) Modification of nociceptor responses by inflammatory mediators and second messengers implicated in their action-a study in canine testicular polymodal receptors. Prog Brain Res 113:115-141.

Molino M, Barnathan ES, Numerof R, Clark J, Dreyer M, Cumashi A, Hoxie JA, Schechter N, Woolkalis M, Brass LF (1997) Interactions of mast cell tryptase with thrombin receptors and PAR-2. J Biol Chem 272:4043-4049.

Moriyama T, Iida T, Kobayashi K, Higashi T, Fukuoka T, Tsumura H, Leon C, Suzuki N, Inoue K, Gachet C, Noguchi K, Tominaga M (2003) Possible involvement of P2Y2 metabotropic receptors in ATP-induced transient receptor potential vanilloid receptor 1-mediated thermal hypersensitivity. J Neurosci 23:6058-6062.

Numazaki M, Tominaga T, Toyooka H, Tominaga M (2002) Direct phosphorylation of capsaicin receptor VR1 by protein kinase Cepsilon and identification of two target serine residues. J Biol Chem 277:13375-13378.

Nystedt S, Emilsson K, Wahlestedt C, Sundelin J (1994) Molecular cloning of a potential proteinase activated receptor. Proc Natl Acad Sci USA 91:9208-9212.
Premkumar LS, Ahern GP (2000) Induction of vanilloid receptor channel activity by protein kinase C. Nature 408:985-990.

Reinshagen M, Rohm H, Steinkamp M, Lieb K, Geerling I, Von Herbay A, Flamig G, Eysselein VE, Adler G (2000) Protective role of neurotrophins in experimental inflammation of the rat gut. Gastroenterology 119:368-376

Saifeddine M, al-Ani B, Cheng CH, Wang L, Hollenberg MD (1996) Rat proteinase-activated receptor-2 (PAR-2): cDNA sequence and activity of receptor-derived peptides in gastric and vascular tissue. Br J Pharmacol 118:521-530.

Seeliger S, Derian CK, Vergnolle N, Bunnett NW, Nawroth R, Schmelz M, Von Der Weid PY, Buddenkotte J, Sunderkotter C, Metze D, AndradeGordon P, Harms E, Vestweber D, Luger TA, Steinhoff M (2003) Proinflammatory role of proteinase-activated receptor- 2 in humans and mice during cutaneous inflammation in vivo. Faseb J 17:1871-1885.

Steinhoff M, Vergnolle N, Young SH, Tognetto M, Amadesi S, Ennes HS, Trevisani M, Hollenberg MD, Wallace JL, Caughey GH, Mitchell SE, Williams LM, Geppetti P, Mayer EA, Bunnett NW (2000) Agonists of proteinase-activated receptor 2 induce inflammation by a neurogenic mechanism. Nat Med 6:151-158.

Sugiura T, Tominaga M, Katsuya H, Mizumura K (2002) Bradykinin lowers the threshold temperature for heat activation of vanilloid receptor 1 . J Neurophysiol 88:544-548.

Tominaga M, Caterina MJ, Malmberg AB, Rosen TA, Gilbert H, Skinner K, Raumann BE, Basbaum AI, Julius D (1998) The cloned capsaicin receptor integrates multiple pain-producing stimuli. Neuron 21:531-543.

Tominaga M, Wada M, Masu M (2001) Potentiation of capsaicin receptor activity by metabotropic ATP receptors as a possible mechanism for ATPevoked pain and hyperalgesia. Proc Natl Acad Sci USA 98:6951-6956.

Tsuzuki K, Kondo E, Fukuoka T, Yi D, Tsujino H, Sakagami M, Noguchi K (2001) Differential regulation of P2X(3) mRNA expression by peripheral nerve injury in intact and injured neurons in the rat sensory ganglia. Pain 91:351-360.

Vergnolle N, Hollenberg MD, Sharkey KA, Wallace JL (1999) Characterization of the inflammatory response to proteinase-activated receptor-2 (PAR2)activating peptides in the rat paw. Br J Pharmacol 127:1083-1090.

Vergnolle N, Wallace JL, Bunnett NW, Hollenberg MD (2001a) Proteaseactivated receptors in inflammation, neuronal signaling and pain. Trends Pharmacol Sci 22:146-152.

Vergnolle N, Bunnett NW, Sharkey KA, Brussee V, Compton SJ, Grady EF, Cirino G, Gerard N, Basbaum AI, Andrade-Gordon P, Hollenberg MD, Wallace JL (2001b) Proteinase-activated receptor-2 and hyperalgesia: a novel pain pathway. Nat Med 7:821-826.

Vu TK, Hung DT, Wheaton VI, Coughlin SR (1991) Molecular cloning of a functional thrombin receptor reveals a novel proteolytic mechanism of receptor activation. Cell 64:1057-1068.

Wood JN, Perl ER (1999) Pain. Curr Opin Genet Dev 9:328-332.

Woolf CJ, Salter MW (2000) Neuronal plasticity: increasing the gain in pain. Science 288:1765-1769.

Yu Z, Ahmad S, Schwartz JL, Banville D, Shen SH (1997) Protein-tyrosine phosphatase SHP2 is positively linked to proteinase-activated receptor 2-mediated mitogenic pathway. J Biol Chem 272:7519-7524. 